\title{
The function of the attitude of Islamic banks in coastal societies in mediating the effect of emotional attachment on the continuance intention of Islamic banks
}

\author{
Nasir Nasir $^{l}$, Syafruddin Chan ${ }^{1 *}$, and Cut Aprilia ${ }^{l}$, \\ ${ }^{1}$ Management Department, Faculty of Economics and Business, Syiah Kuala University, Indonesia
}

\begin{abstract}
This study aims to analyse the factors that cause the reluctance of Islamic bank customers in coastal areas to be loyal to the particular banks. The population in this study are conventional bank customers who live in Aceh, North Sumatra and Riau. The sample size in this study was 350 respondents. Sampling was carried out using a stratified random sampling method with the following proportions: Aceh $25 \%$, North Sumatra 50\% and Riau 25\%. In this study, the sampling method used the census technique. Data analysis used SEM (Structural Equation Modelling) to verify the path of the relationship between variables. The results showed that of the 3 direct hypotheses tested, the effect of Emotional Attachment on Attitude. The effect of emotional attachment on continuance intention, the effect of Attitude on continuance intention, all of which show a significant effect. The significance that occurs in this direct test indicates that there is a match between the research model developed and the facts in which this research was conducted. On the indirect effect tested, although it showed significant results, the role of attitude in mediating the effect of emotional attachment on continuance intention through attitude is partial.
\end{abstract}

\section{Introduction}

Indonesia, as a Muslim majority country that is dominated by middle class population is a prospective market for Islamic banking [1]. However, the road to success for Islamic banking in Indonesia is not a smooth sailing. According to the Financial Services Authority of Indonesia or "OJK" in the beginning of the establishment, Islamic banking did not attract the attention of Indonesian.

The current phenomenon is the low penetration of coastal communities, which are dominated by the fishery sector, to the bank services, both for savings products, micro-credit, transfer/payment facilities, and the use of EDC machines. Although many efforts have been made to improve access to banking services in these coastal communities, these efforts have not been fully successful. Penetration to Islamic banks among coastal communities only occurred when "the qanun" for Islamic financial institutions was enacted in Aceh which made all banking services in Aceh based on sharia. Even if there is a switch, there is no guarantee that they will stay there and not switch back to conventional banks. From previous research conducted by [2] revealed that there are still material and infrastructure aspects that are the reluctance of conventional bank customers to switch to Islamic banks. Many of them prioritize rational aspects such as more facilities, more advanced technology, better benefits and cheaper transaction costs than Islamic banks [3]. The question is whether it is the mere rationality aspect that is considered by consumers to continue using Islamic bank products. Other researchers [4] are revealing the aspect of religiosity asone of the differentiators. The higher people's level of religiosity, the higher the probability of switching to an Islamic bank.especially those related to the aspect of unsury which is forbidden in Islam [5]. However, according to [1] there are still doubts among customers, especially Muslims, regarding the implementation of the business, is it really sharia and compliance with Islamic law? If they are not sure about this, it will certainly raise doubts about continuing to use (continuance intention) Islamic banking products even among sharia customers themselves [6].

Continuance intention is the study that measures customer intention to continue using/purchasing a product/service [7]. Numerous scholars stated that the sustainability of business depends on the continuity of product/service consumption. Therefore, to further increasing the performance of Islamic banking, it is important to measure the predictors of continuance intention of Islamic banking customers.

Consumer decision to continue or discontinue purchasing a product/ service depends on their evaluation of the performance of the product and their state of emotion. According to [8] customers emotional state affect their decision. While, through service quality, consumer can measure the overall performance of the service offered [9].

Many previous studies have discussed the determinants of the continuance intention factors for Islamic banking products, as was done by [10] that

* Corresponding author: syafruddin.chan@unsyiah.ac.id 
prioritizes aspects of technology, product features and other benefits. However, as far as the author's knowledge, discussing aspects of emotional attachment and attitude as an antecedent of continuance intention has not been done much.

This study aims to measure the role of emotional attachment and attitude in predicting consumers' continuance intention to use Islamic banking products/services for financial transactions.

\section{Literature Review}

\subsection{Emotional attachment}

Originated from the study of psychology, emotional attachment is considered as an emerging construct in consumer behaviour study [11]. The scholars of marketing science believed that the attachment that human feel on each other also applied to objects like product and place [12].Therefore according to [13] elucidated emotional attachment as a reflection of consumers feeling or mental state that is associated with a brand.

Building an emotional attachment between consumer and brand is important for a company [13]. stated that an emotional attachment consumers have a strong relationship with the brand and commitment to keep the relationship going by giving a positive behaviour. The study done by [11] found that brand attachment has a significant effect on continuance intention to use mobile apps. [14] also found that emotional attachment leads consumers to support the brand, purchase the brand and have an intention to continue purchasing and consuming the brand. Hence, this study hypotheses that:

H1: The effect of emotional attachement on attitude

H2: Emotional attachment influence continuance intention

\subsection{Attitude}

In the context of marketing, the attitude formed is related to buying behaviour, actual experience, and product trials [15]. Attitudes are formulated from the media and from advertising messages or other promotional tools, such as direct marketing or the internet, and through words of mouth received from others who have tried the product [16]. There is a direct relationship between attitude and behaviour. Attitude can lead to or result in behaviour, but these terms are not interchangeable or synonymous. Behaviour reflects positive or negative evaluations and actions towards the object of attitude [17]. Attitudes have motivational factors, as they may drive consumers towards certain actions or may hinder certain behaviours [18].

Attitude consists of three main elements: cognitive, affective, and conative [19]. This is the tri-component attitude model adopted in this study. Cognitive elements relate to the types of information, data, knowledge, and perceptions collected by consumers [20]. The source of the data and knowledge is direct experience with the attitude object itself. This information and knowledge is formulated in the form of trust. Consumers believe that attitude objects have certain benefits and features or that certain behaviours or actions will lead to certain outcomes and preferred outcomes [19]. The affective element is related to the feelings and emotions that consumers have towards the attitude object. Consumer researchers, consider respondents' emotions as a factor that helps consumers in evaluating attitude objects [15]. The emotional element is the main factor involved in judging attitude objects, because consumers tend to classify objects as favourable or unfavourable based on their emotions [19]. The conative element is the action taken by the individual in relation to the attitude object. The action can be in the form of a consumer's tendency to buy their actual intention to buy an attitude object. In measuring the conative element, marketers assess buyer intentions on a certain scale to measure the probability of purchasing decisions or behaviour [19].

H3: Attitude influence continuance intention

\subsection{Continuance Intention}

Continuance intention is part of behavioural intention that describes a consumer willingness to continue consuming a service in the stage of post consumption [21]. It is an important construct to measure due to its ability to influence actual consumption [22]. According to [21] consumer continuance intention is the combination of intentional, rational, and emotional response. Therefore, consumers' perception on the bank service performance and their attachment to the bank contributes on their decision to continue or discontinue to consume the bank's service.

H4: Emotional attachment influence continuance intention through attitude

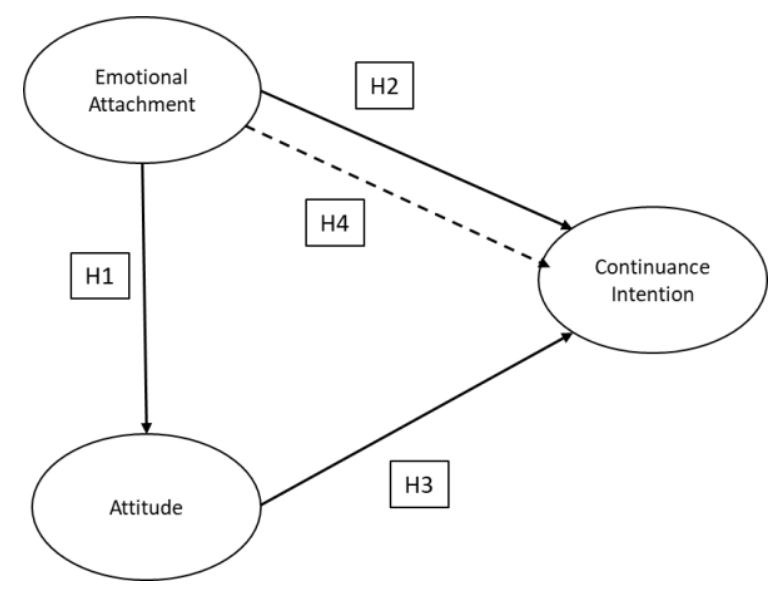

Fig. 1. Conceptual Framework

\section{Research methods}

\subsection{Sample Design and Data Collection}

The population in this study are conventional bank customers who live in coastal area in Aceh, North Sumatra and Riau. The size of the sample in this study was 350 respondents [23]. Sampling was carried out using a cluster random sampling method with the 
following proportions: Aceh 25\%, North Sumatra 50\% and Riau $25 \%$. The proportion of North Sumatra is larger because the number of bank customers in North Sumatra is also larger than Aceh and Riau

\subsection{Data analysis}

The data analysis technique in this research is descriptive and verification. Descriptive analysis was conducted to assess the demographic profile of the respondents and the internal consistency of construction. While the verification analysis uses SEM (Structural Equation Modelling) to verify the path of the relationship between the variables in this study. In addition, the SEM analysis software is IBM SPSSAMOS version 22.

\section{Results and Discussion}

\subsection{Characteristics of Respondents}

In terms of age, the most respondents came from the age group 30-40 years, namely $199(56 \%)$. regarding the gender, there are more men than women, namely 250 (71.4\%). Then from the educational background the majority are those with undergraduate education, namely $175(50 \%)$. Most of their jobs are in the fishery sectors $188(53.7 \%)$, the rest $162(46.2 \%)$ work outside the fisheries sector such as trade, culinary and other tourism services.

\subsection{Validity with Measurement Model}

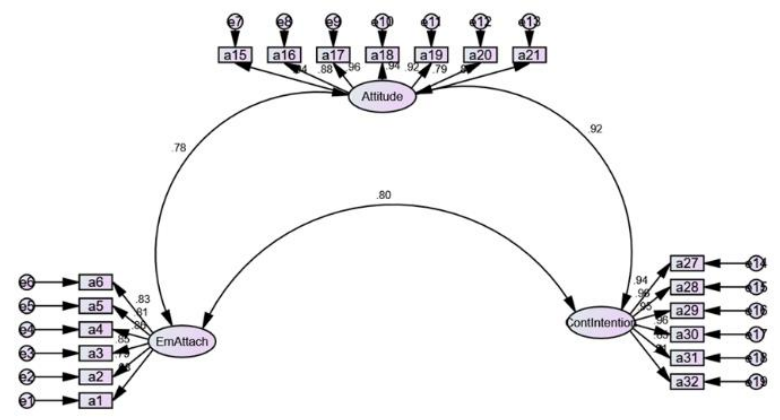

Fig. 2. Initial Measurement Model

Item validity is indicated by the existence of a correlation or support for the total item (total score), the calculation is done by correlating the item score with the total item score. If we use more than one factor, it means testing the validity of the item by correlating the item score with the factor score, then continuing to correlate the item score with the total factor score (the sum of several factors). An indicator is said to be valid if it has a standardized loading factor value $>0.50$. For indicators that do not meet the requirements will be eliminated from the model. From the results of calculations that have been carried out, it turns out that all indicators contained in this model have a loading factor value of $>0.50$, so it can be said that all of them are valid and nothing should be eliminated. The loading factor can be seen in the Table 1 .
Table 1. New Loading Factor

\begin{tabular}{|ccc|c|}
\hline & & & Estimate \\
\hline a1 & $<---$ & EmAttach & .683 \\
a2 & $<---$ & EmAttach & .792 \\
a3 & $<---$ & EmAttach & .849 \\
a4 & $<---$ & EmAttach & .859 \\
a5 & $<---$ & EmAttach & .813 \\
a6 & $<---$ & EmAttach & .829 \\
a15 & $<---$ & Attitude & .935 \\
a16 $<---$ & Attitude & .878 \\
a17 $<---$ & Attitude & .956 \\
a18 $<---$ & Attitude & .937 \\
a19 $<---$ & Attitude & .916 \\
a20 & $<---$ & Attitude & .787 \\
a21 $<---$ & Attitude & .850 \\
a27 $<---$ & ContIntention & .944 \\
a28 & $<---$ & ContIntention & .959 \\
a29 & $<---$ & ContIntention & .951 \\
a30 & $<---$ & ContIntention & .957 \\
a31 $<---$ & ContIntention & .853 \\
a32 & $<---$ & ContIntention & .815 \\
\hline
\end{tabular}

Based on the table above, it can be explained that all the variable items used in this study are all valid, because they have a loading factor number $>0.50$.

\subsection{Fit Model}

Table 2. Modification Indices

\begin{tabular}{|c|c|c|c|}
\hline ITEMS & & ITEMS & MI \\
\hline e12 & $<-->$ & e13 & 33,142 \\
\hline e19 & $<-->$ & EmAttach & 31,373 \\
\hline e6 & $<-->$ & Attitude & 31,183 \\
\hline e6 & $<-->$ & e16 & 28.893 \\
\hline e1 & $<-->$ & e2 & 25,374 \\
\hline e1 & $<-->$ & e3 & 25,033 \\
\hline e9 & $<-->$ & EmAttach & 22.02 \\
\hline e17 & $<-->$ & Attitude & 19,809 \\
\hline e2 & $<-->$ & e3 & 19.262 \\
\hline e10 & $<-->$ & e13 & 16,577 \\
\hline e18 & $<-->$ & e19 & 15,708 \\
\hline e8 & $<-->$ & e11 & 13,677 \\
\hline
\end{tabular}

Model fit at the measurement stage is one of the requirements in SEM to see if there is a feasibility of a model that has been developed through a literature review process with data collected from the field in the form of primary data. A model is said to be fit with the existing data if it meets several criteria tested at the goodness of fit test stage. The criteria used include CMIN/DF, GFI, TLI, IFI and RMSEA. At the time of initial testing, it turned out that there were several fit criteria that were not met, therefore it was necessary to modify the model referring to the modification indices table (Table 2). 
Based on the modification indices table above, modifications were made to the model so that the results of the model modification, after adding some covariance lines as suggested by the MI table, are shown in the Figure 3 .

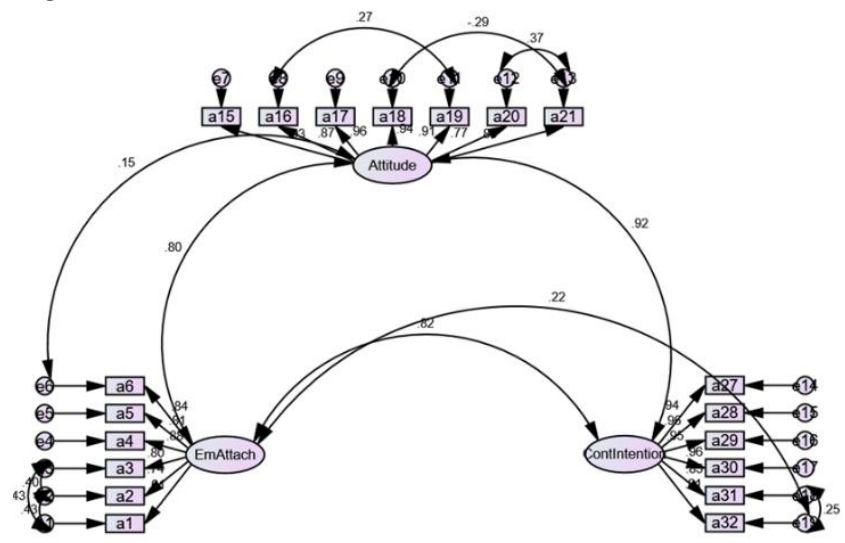

Fig. 3. Measurement Model after Modification

After modifying the model, it turns out that some criteria that were not fit before, such as CMIN/DF and RMSEA, are now better and have become fit. The cut off values for each criterion and test results before and after model modification can be seen in the Table 4 .

Table 4. Goodness of Fit

\begin{tabular}{|c|c|c|c|c|c|}
\hline No & Criteria & $\begin{array}{c}\text { Cut off } \\
\text { value }\end{array}$ & $\begin{array}{c}\text { Value } \\
\text { Before }\end{array}$ & $\begin{array}{c}\text { Value } \\
\text { After }\end{array}$ & $\begin{array}{c}\text { Fit/N } \\
\text { ot Fit }\end{array}$ \\
\hline 1 & CMN/DF & $<2.00$ & 3,602 & 1.902 & Fit \\
\hline 2 & GFI & $>0.90$ & 0.787 & 0.901 & Fit \\
\hline 3 & TLI & $>0.90$ & 0.921 & 0.962 & Fit \\
\hline 4 & IFI & $>0.90$ & 0.932 & 0.969 & Fit \\
\hline 5 & RMSEA & $<0.08$ & 0.107 & 0.065 & Fit \\
\hline
\end{tabular}

\subsection{Reliability Test}

The reliability test intended in this study is to determine the extent to which the measurement results remain statistically consistent, namely by calculating the magnitude of the composite reliability of the data based on the estimated output obtained using Cronbach alpha. The results are as described in Table 4.3 which shows that the instrument in this study is reliable because its reliability coefficient value is greater than 0.60 [24].

Table 3 Reliability Using Cronbach Alpha (CA)

\begin{tabular}{|c|c|c|c|}
\hline No & Variable & CA & Information \\
\hline 1 & $\begin{array}{c}\text { Emotional } \\
\text { attachment }\end{array}$ & .918 & Reliable \\
\hline 2 & Attitude & .966 & Reliable \\
\hline 3 & $\begin{array}{c}\text { Continuance } \\
\text { intention }\end{array}$ & .967 & Reliable \\
\hline
\end{tabular}

Based on the reliability analysis, it can be seen that the alpha for each respondent's perception variable can be seen from several variables Emotional attachment is
$91.8 \%$, Attitude is $96.6 \%$ and Continuance intention is $96.7 \%$. Thus the reliability measurement of the research variables shows that the reliability measurement meets the requirements of Cronbach Alpha (CA) where the CA coefficient value is at least or greater than 60 percent.

\subsection{Hypothesis Testing}

Hypothesis test verification in this study was conducted to test and analyze the effect of Emotional Attachment, Attitude and Continuance Intention to use Islamic banking products and services. The verification hypothesis testing consists of testing the direct influence hypothesis and testing the indirect effect hypothesis. The results of testing the direct influence hypothesis can be seen in the following figure and table.

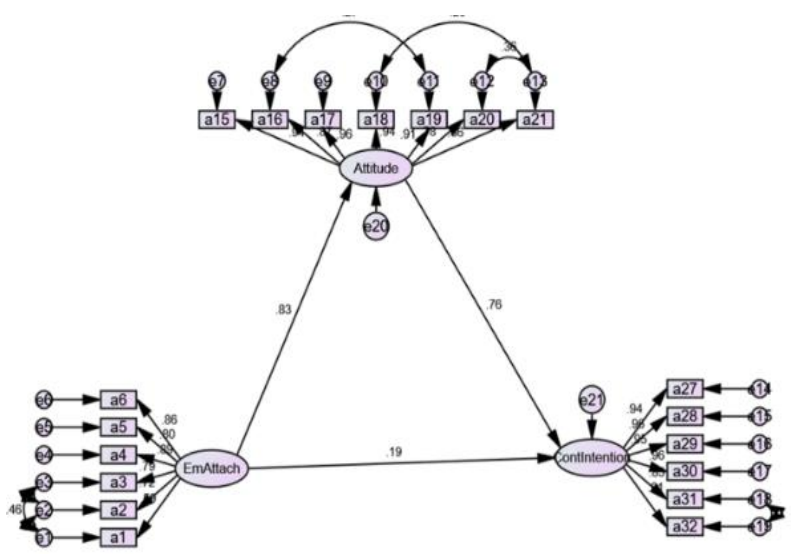

Fig. 4. Structural Model

Table 5. Hypothesis Testing

\begin{tabular}{|ccc|ccc|}
\hline & & & CR & P & Beta \\
\hline Attitude & $<---$ & EA & 9.073 & $* * *$ & .825 \\
CI & $<---$ & Attitude & 12.356 & $* * *$ & .762 \\
CI & $<---$ & EA & 3.116 & .002 & .191 \\
\hline
\end{tabular}

EA: Emotional attachment

CI: Continuance intention

H1: The effect of Emotional Attachment on Attitude

Testing the effect of Emotional Attachment on Attitude shows a CR value of 9.073 and with a probability value of $* * *$. The two values obtained have met the requirements for the acceptance of $\mathrm{Ha}$, namely the $\mathrm{CR}$ value should be greater than 1.96 and the probability value is less than 0.05 . The magnitude of the coefficient of the effect of Emotional Attachment on Attitude is 0.825

H2: The effect of Emotional Attachment on Continuance Intention

Testing The effect of Emotional Attachment on Continuance Intention shows a CR value of 12,356 and with a probability value of $* * *$ Thus it can be stated that the effect of Emotional Attachment on Continuance Intention is significant. The magnitude of the coefficient 
of the effect of Emotional Attachment on Continuance Intention is 0.762

\section{H3: The effect of Attitude on Continuance Intention}

Testing the effect of Attitude on Continuance Intention shows a CR value of 3.116 and with a probability of .002 . The two values obtained have met the requirements for acceptance of Ha. The magnitude of the coefficient of the effect of Attitude on Continuance Intention is 0.191 .

H4: The Effect of Emotional Attachment on Continuance Intention through Attitude

Testing the Effect of Emotional Attachment on Continuance Intention through Attitude shows a probability of .001 . The $p$ value obtained has met the requirements for acceptance. Ha. The coefficient of the Effect of Emotional Attachment on Continuance Intention through Attitude is 0.629 or $62.9 \%$.

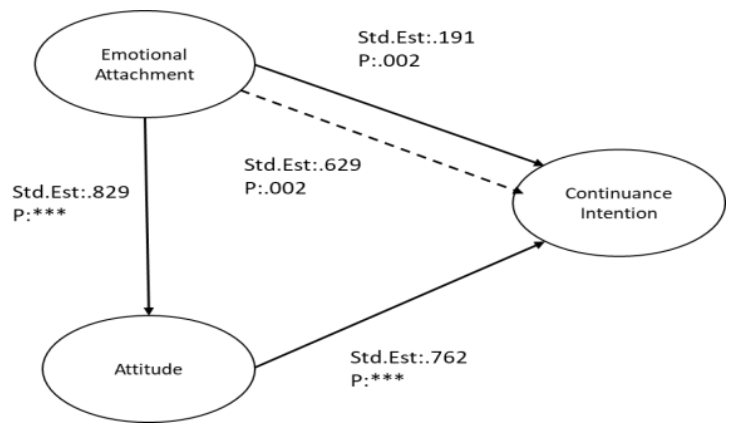

Fig. 5. The Effect of Emotional Attachment on Continuance Intention through Attitude

Because the direct effect of emotional attachment on continuance intention is significant and the indirect effect of the effect of emotional attachment on continuance intention through attitude is also significant, we can say that the role of attitude in mediating these two variables is a Partial Mediating.

\section{Discussion}

Of the 3 direct hypotheses tested, the effect of Emotional Attachment on Attitude, The effect of Emotional Attachment on Continuance Intention, The effect of Attitude on continuance intention, all of which show a significant effect. The significance that occurs in this direct test indicates that there is a match between the research model developed and the facts in which this research was conducted.

Based on the results or findings presented in the previous section, it means that Emotional Attachment and Attitude are indeed determinant variables -in improving the intention of continuance bank's customer in using Islamic banking. The management can use these two variables as tools to improve the intention of the bank's customer to continue using Islamic banking. This result is in line with research conducted by [12].

To support the strongest increase in the intention to use Islamic banking services, it can be done through the increasing of attitude, because this variable has the largest magnitude number compared to the other variables, namely $82.5 \%$ compared to emotional attachment which is only $19.1 \%$. On the indirect effect tested, although it showed significant results, the role of attitude in mediating the effect of emotional attachment on continuance intention through attitude is quite good. The path of the effect of emotional attachment on continuance intention through attitude has a coefficient of $62.5 \%$

\section{Conclusion}

From the research findings that have been discussed in the previous section, we can see that the main factor that can increase coastal societies interest in continuing to use Islamic banking services is to increase the customer's positive attitude towards Islamic bank products. Because this factor has the highest coefficient compared to other variables. This attitude improvement must of course be accompanied by an integrated marketing program, including generating emotional feelings about the importance of using Islamic banks in conducting financial transactions, especially for customers who are Muslim, because this banking product is free from usury.

On the other hand, the Islamic banking business practices carried out must also follow sharia business practices in a "kaffah" manner, so that there is no impression, Islamic banks are only the casing in an effort to attract the sympathy of Muslims to make Islamic banks an institution where they entrust financial transactions, saving, borrowing and lending.

Further suggestions that need to be conveyed to sharia business actors, in addition to the sharia financial regulations that have been initiated in Aceh, are also necessary to issue regulations for the conversion of nonbank financial institutions such as sharia-based health and loss insurance, and management of labour social security funds with sharia schemes.

\section{References}

1. D. Suhartanto, J Islam Mark 10, 4 (2019)

2. S. Ayyub, Xuhui W, Asif M, Ayyub RM, Int J Islam Middle East Finance Manag 13, 1 (2019)

3. I. Muslichah, Sanusi S, Asian J Islam Manag 1, 2 (2019)

4. H. Basri, Tabrani M, Management and Financial Transparency of Islamic Religious Organizations: The Case Study of Modern Islamic Boarding School in Contemporary Indonesia, Glob J Humanit Soc Sci [Internet]. 2015 [cited 2016 Jun 28]

5. H. Usman, Projo NWK, Chairy C, Haque MG. The exploration role of Sharia compliance in technology acceptance model for e-banking (case: Islamic bank in Indonesia), J Islam Mark, (2021)

6. N. Tara, Irshad M, Khan MR, Yamin M, Rizwan M, J Public Adm Gov 4, 3 (2014)

7. H.L. Song, Customer adoption of internet banking: An integration of TAM with trust, perceived risk, 
and quality. In: Proceedings - 2010 2nd

International Conference on Multimedia

Information Networking and Security, MINES

(2010)

8. J. Gountas, Gountas S, J Bus Res, (2007)

9. H. Chahal, Manag Serv Qual An Int J [Internet]. (2010)

10. H. Herjanto, M. Amin, Int J Bank Mark, 38, 6 (2020)

11. C. Y. Li, Y. H. Fang, Predicting continuance intention toward mobile branded apps through satisfaction and attachment, Telemat Informatics (2019)

12. P. Cheng, Z. OuYang, Y. Liu, Transp Res part A policy Practice 124 (2019)

13. S. Levy, H. Hino, Int J Bank Mark, (2016)

14. A. S. Prastyaningsih, Suyadi I, Yulianto E, J Business Adm 16, 1 (2014)

15. M. M. H. Abou-Youssef, W. Kortam, E. AbouAish, N. El-Bassiouny, Int J Bank Mark 33, 6 (2015)

16. N. Souiden, M. Rani, Int J Bank Mark 33, 2 (2015)

17. J. Bananuka, M. Kasera, G.M. Najjemba, D. Musimenta, B. Ssekiziyivu, S. N. L. Kimuli, J Islam Mark 11, 1 (2019)

18. M. Janssen, M. Mntymäki, J. Hidders, B. Klievink, W. Lamersdorf, B. van Loenen, Open and Big Data Management and Innovation: 14th IFIP WG 6.11 Conference on e-Business, eServices, and e-Society, I3E 2015 Delft, The Netherlands, October 13-15, 2015 Proceedings. Lect Notes Comput Sci (2015)

19. L. Schiffman, L. L. Kanuk. Consumer Behavior (seventh edition) consumer behavior. Jakarta PT Index Qual Res net" Syst Versus Interpret Anal with two CAQDAS Packag Nvivo MAXQDA. (2008)

20. A. Kaakeh, M.K. Hassan, S.F. Van Hemmen Almazor, Int J Emerg Mark 14, 4 (2019)

21. J. Hepola, M. Leppäniemi, H. Karjaluoto, J Retail Consum Serv 57 (2020)

22. A.S. Oertzen, G. Odekerken-Schröder, Int J Bank Mark, (2019)

23. J.F. Hair, WC Black, BJ Babin, RE Anderson, RL Tatham, Prentice hall Upper Saddle River, NJ 5 (1998)

24. L.R. Kahle, N.K. Malhotra, J Mark Res [Internet] 31, 1 (1994) 